\title{
The reliability of a computer interview for drug use/abuse information
}

\author{
HAROLD ERDMAN, MARJORIE H. KLEIN, and JOHN H. GREIST \\ University of Wisconsin, Madison, Wisconsin 53792
}

\begin{abstract}
A computer interview was developed to collect information about drug use/abuse from high school students. Responses to this interview were compared with those obtained from an identical paper-and-pencil questionnaire given to the same students, in counterbalanced order. Results were comparable for the two methods, but missing data and logically inconsistent answers obtained with the paper-and-pencil questionnaire were not possible with the computer interview. The overwhelming majority of respondents preferred the computer interview as a means of data collection.
\end{abstract}

A major problem in the field of drug and alcohol research has been the difficulty of collecting accurate and complete data from respondents in a cost-effective manner. Personal interviews are costly, and it is often difficult to establish rapport with respondents who are guarded, sensitive, or simply concerned about their drug or alcohol use. Questionnaire surveys, especially if anonymous, are easier for both respondents and researchers, but they run the risk of bias from missing data and inconsistent responding. Unless specific or general validity information is available (very difficult if not impossible to collect in anonymous studies), it is very hard to even estimate the reliability of questionnaires or to know the rates of respondent over- or underreporting. All of these problems are increased in research in high schools or middle schools, in which young people may also fear exposing themselves to teachers, school or community authority figures, parents, or even peers.

The purpose of the present investigation is to study the effectiveness of a computer interview for collecting information concerning drug use/abuse from high school students. Extensive previous work with computer interviewing in medical and psychiatric settings suggests that the method might be particularly useful for collecting this sort of sensitive data (Greist, Klein, Gurman, \& Van Cura, 1977; Greist, Klein, \& Van Cura, 1973; Klein, Greist, \& Van Cura, 1975; Van Cura, Slack, \& Frey, 1971). In previous research with a range of sensitive subjects (e.g., sexuality, drug and alcohol use, psychiatric symptoms, etc.), the more deviant and/or potentially embarrassing the content of questions, the less free or comfortable the respondents found a personal interview. Even patients who thought it was important

This research was supported in part by a grant from NIDA (1 R01 DA 000903), by a Research Scientist's Development Award (1-K1-MH-70 903, to Dr. Greist), and by the Wisconsin Psychiatric Research Institute. We wish to thank Lisa Loder and Sandra Bass for their help in carrying out the research and Jean Clatworthy for helping prepare this manuscript. to convey information about socially deviant behavior to treatment personnel were sometimes inhibited by concerns about interviewer reactions and judgments. Even those individuals who preferred a human interviewer completed the computer interviews; most found the experience interesting.

Aside from being an attractive and appealing method of data collection, the computer interview may also be superior to paper-and-pencil methods because it can be designed and programmed so that respondents must either complete all appropriate lines of questioning or specify their desire not to respond. Options to indicate that questions are unclear or terminology is not understood can also be provided, and definitions of terms or rephrased questions may increase the likelihood of meaningful data. By contrast, questionnaires are sometimes abandoned half-completed or inadequately and erroneously filled out. Another advantage of the computer interview is that data are immediately stored as they are collected. Finally, the capacity of the computer to be modeled after the flow of a personal interview means that repetition and redundancy can be avoided while necessary details in specific areas can be obtained. Branching logic that is not possible with a paper-andpencil questionnaire enables the interview to flow naturally, concentrating on relevant questions, picking up missed information, and even tailoring future questions to the respondents' particular characteristics (e.g., questions about parental and peer use made relevant to the respondent's living situation). Free text response formats also allow respondents to express themselves in detail after responding to more "set" multiple-choice questions.

\section{METHOD}

\section{Computer Interviewing Technique}

The computer procedure is similar to that used in other medical and psychiatric settings (Greist, Klein, \& Van Cura, 1973; Greist, Van Cura, \& Kneppreth, 1973; Slack, Hicks, Reed, \& Van Cura, 1966). Subjects are directly interviewed at 
a computer terminal with a typewriter keyboard. Respondents are first taught the interview procedure by a computer-assisted instruction section. This part of the program also assesses the individual's alertness, comprehension, and general mastery of the computer interviewing process before permitting him or her to begin the questions.

\section{Drug/Alcohol Use/Abuse Interview}

Two versions of the same questionnaire were designed for use in the schools: a paper-and-pencil form and a computer interview form. Both questionnaires were similar, although the computer interview was designed to branch around inappropriate questions and sometimes to elicit greater detail. Thus, present smokers, nonsmokers, and past smokers might all receive different smoking sequences. Questions for these methods were drawn from questionnaires in use by other investigators in the drug abuse risk prediction field (Kandel, 1973; Kandel \& Faust, 1975; Smith \& Fogg, 1974). We also added other material. Areas covered included basic demographic information and the students' use or abuse of various licit and illicit drugs, including cigarettes, alcohol, marijuana, and hallucinogens. Other questions covered peer and parental drug use patterns, attitudes toward drug use, reasons for drug use or nonuse, detailed questions about the circumstances in which drug use occurred, questions about symptoms of emotional and physical distress, and questions about attitudes toward school and functioning in school. The interviews and questionniares ended with a series of items covering the respondents' attitudes toward the questionnaire, including a choice of preferred method, computer vs. paper and pencil (Slack \& Van Cura, 1968).

\section{Design of Reliability Study}

The basic counterbalanced design called for the student respondents to respond to both methods, the computer interview and the paper-and-pencil questionnaire. All interviews and questionnaires were done in one urban public high school with 2,300 students. Participation was voluntary and took place during students' free periods. A small monetary incentive (\$1) was offered to encourage students to participate. Interviews and questionnaires were anonymous; participants were identified by a code name. A sample of 133 students used both methods in counterbalanced order. Kappa (Cohen, 1960, 1968) was used as the measure of agreement between the two methods.

\section{RESULTS}

\section{The Computer and Paper-and-Pencil Methods}

A direct comparison was made of responses to both methods on a number of questions concerning drug and alcohol use and related issues (see Table 1). Agreement between the two methods was particularly high (kappas ranging from .65 to .86) for respondents" "yes-no" reports of their own cigarette and drug use and for their "yes-no" reports of parent alcohol and drug use and peer drug use. There was somewhat less agreement, although still substantial, regarding alcohol use. The low agreement regarding subjects own alcohol use was mostly due to their responding "no" concerning their use on the computer and "yes" on the paper-and-pencil interview. Single, Kandel, and Johnson (1975), in a comparison of responses on a repeated paper-and-pencil questionnaire also found greater disagreement regarding alcohol than marijuana or other illicit substances.

The same pattern was revealed when we examined reported frequency of use of the various substances. In general, there was better agreement for cigarettes and drugs than for alcohol. Subjects who reported no use on

Table 1

Comparison of Computer and Paper-and Pencil Methods for Use, Nonuse, and Frequency of Use (Percent for $N=133$ )

\begin{tabular}{|c|c|c|c|c|c|}
\hline & \multirow{2}{*}{\multicolumn{3}{|c|}{ Computer and Paper and Pencil Agree }} & \multicolumn{2}{|c|}{ Kappa } \\
\hline & & & & \multirow{2}{*}{$\begin{array}{c}\text { For Use } \\
\text { (Yes/No) }\end{array}$} & \multirow{2}{*}{$\begin{array}{l}\text { Weighted for } \\
\text { Frequency of Use }\end{array}$} \\
\hline & Use & Nonuse & Both & & \\
\hline \multicolumn{6}{|c|}{ Respondent } \\
\hline Cigarettes & 86 & 10 & 96 & .82 & .87 \\
\hline Alcohol & 95 & 1 & 96 & .28 & .59 \\
\hline Beer & 72 & 8 & 80 & .41 & .64 \\
\hline Wine & 43 & 20 & 63 & .53 & .44 \\
\hline Hard Liquor & 60 & 14 & 74 & 47 & .50 \\
\hline Drunk & 77 & 14 & 91 & .70 & .55 \\
\hline Marijuana & 65 & 22 & 87 & .82 & .79 \\
\hline Marijuana and Drugs & 73 & 17 & 89 & .73 & .77 \\
\hline \multicolumn{6}{|c|}{ Father } \\
\hline Alcohol & 87 & 8 & 95 & .78 & .83 \\
\hline Drug & 12 & 69 & 81 & .65 & \\
\hline \multicolumn{6}{|c|}{ Mother } \\
\hline Alcohol & 80 & 11 & 91 & .79 & .80 \\
\hline Drug & 22 & 63 & 85 & .86 & \\
\hline \multicolumn{6}{|c|}{ Peers } \\
\hline Alcohol & 96 & 0 & 96 & .00 & .55 \\
\hline Marijuana & 93 & 2 & 95 & .53 & .64 \\
\hline Other Drug & 46 & 37 & 83 & .65 & .72 \\
\hline
\end{tabular}

Note-Ns are somewhat less for parental reports. Percent agreement for eight drug categories averaged $90 \%$. Reports of use ranged from none for heroin to $21 \%$ for stimulants; average $=8 \%$. Frequency was not assessed for parental drug use other than alcohol. 
the computer reported significantly greater frequency of alcohol use in all alcohol categories on the paperand-pencil questionnaire (Wilcoxon test, $p<.05$ to $\mathrm{p}<.0001$ ). These differences were reflected in weighted kappas for all subjects combined, which ranged from a low of .44 (for wine) to a high of .87 for cigarettes.

Respondent attitudes toward alcohol and marijuana (rated on a global 7-point scale) showed somewhat less agreement between methods. Weighted kappas ranged from .39 to .66 (averaging .52). Methods seem to contribute equally to this difference, except that marijuana users report more positive attitudes toward the computer. Finally, for reports of parent and peer use and attitudes, as well as respondents' school attendance and psychological symptoms, we found no significant differences between methods. Agreement was aiso high for respondent reports of school attendance (weighted kappa $=.76)$ and somewhat lower, but still substantial, for reports of psychological state (weighted kappas ranged from .51 to .57 , averaging .55 ).

On the whole, the two methods yielded very similar results, although the computer interview elicited some lower reported frequencies of alcohol consumption and marijuana use.

\section{Respondent Evaluation and Preferences for \\ Computer and Paper-and-Pencil Methods}

Both methods were seen positively, but subjects found the computer interview significantly more inter. esting than the written questionnaire (Wilcoxon test, $\mathrm{p}<.0001$ ).

When asked to indicate the method that they preferred after they had taken both methods, respondents overwhelmingly picked the computer over the paperand-pencil questionnaire, by a margin of about 7 to 1 . The computer was so popular that more subjects returned for a second interview or questionnaire than could always be accommodated.

\section{CONCLUSION}

Our respondents clearly found the computer interview more attractive and appealing. This, combined with the computer interview's ability to obtain complete data, to check for response inconsistencies, and to give immediate feedback, makes it a particularly attractive method in surveys in which subject motivation is a potential problem. The capacity of the computer interview to branch, to alternate questions with information giving (e.g., teaching), and to go into necessary detail makes it especially relevant for fairly complex question sets. Thus, while the computer and pencil-and-paper methods seem to collect similar information, the computer may be superior with respect to factors such as subject evaluations and cooperation and the completeness of the data obtained.

\section{REFERENCES}

Cohen, J. A coefficient of agreement for nominal scales. Educational Psychology Measures, 1960, 20, 37-46.

Coken, J. Weighted kappa: Nominal scale agreement with provision for scaled disagreement or partial credit. Psychological Bulletin, 1968, 70, 213-220.

Greist, J. H., KLeIN, M. H., Gurman, A. S., \& Van Cura, L. J. Computer measures of patient progress in psychotherapy. Psychiatric Digest, 1977, 38, 23-30.

Greist, J. H., KLein, M. H., \& Van CuRa, L. J. A computer interview for psychiatric patient target symptoms. Archives of General Psychlatry, 1973, 29, 247-253.

Greigt, J. H., Van Cura, L. J., \& Kneppreth, N. P. A computer interview for emergency room patients. Computers and Biomedical Research, 1973, 6, 257-265.

KANDEL, D. The role of parents and peers in adolescent marijuana use. Science, 1973, 181, 1067-1070.

KandeL, D., \& Faust, R. Sequence and stages in patterns of adolescent drug use. Archives of General Psychiatry, 1975, 32, 923-932.

KueIn, M. H., Greist, J. H., \& VAn Cura, L. J. Computers and psychiatry: Promises to keep. Archives of General Psychiatry, $1975,32,837-843$.

Sinale, E., Kandel, D., \& Johnson, B. D. The reliability and validity of drug use responses in a large scale longitudinal survey. Journal of Drug Issues, 1975, 5, 426-443.

Slack, W. V., Hicks, G. P., ReEd, C. E., \& Van Cura, L. J. A computer based medical history system. New England Journal of Medicine, 1966, 274, 194-198.

Slack, W. V., \& Van Cura, L. J. Patient reaction to computerbased medical interviewing. Computers and Biomedical Research, $1968,1,527-531$.

Smith, G. M., \& Foco, C. P. Teenage drug use: A search for causes and consequences. Personality and Social Psychology Bulletin, 1974, 1, 426-429.

Van Cura, L. J., Slack, W. V., \& Frey, S. R. Elements of a computer medical interview system. Biomedical Sciences Instrumentation, 1971, 8, 33-42.

(Received for publication April 2, 1982; revision accepted September 23, 1982.) 